\title{
$\mathrm{TFT}-\mathrm{LCD}$ 생산공정을 위한 실리콘 펌프 및 제어시스템에 관한 연구 \\ 박형근 ${ }^{*}$ \\ ${ }^{1}$ 남서울대학교 전자공학과
}

\section{Study on the Silicon Pump and Control System for TFT-LCD Manufacturing Process}

\author{
Park Hyoung-Keun ${ }^{1^{*}}$ \\ ${ }^{1}$ Deptment of Electronic Engineering, Namseoul University
}

\begin{abstract}
요 약 본 연구에서는 LCD 생산라인에서 장기적으로 정체상태에 있는 모듈의 수율을 높이고, 현재 TFT-LCD 생산 공정에 필수적인 고압의 실리콘주입 장비 및 정밀 제어시스템을 개발하였다. 본 개발을 통하여 향후 본격생산을 준비 중인 차세대 디스플레이 생산라인뿐만 아니라 중국으로 이전중인 LCD 생산 설비의 라인 환경에서 장비의 효율을 최 대한 발휘함으로써 신규 투자비용을 최소화하고 최대의 효과를 창출할 수 있도록 세부 동작 시퀀스를 제어하기 위한 $\mathrm{H} / \mathrm{W}$ 와 S/W 시스템을 생산라인에 실장하였다. 또한, Fast-evacuating을 위한 Vacuum pump 구조를 제안하고 Pump control 회로 설계 및 실험을 통해 제품화하였다.
\end{abstract}

\begin{abstract}
In this study, the yield of the modules in LCD production lines, improving current TFT-LCD production process is essential for high-pressure silicone injection equipment, and precision control system was developed. This full-scale production of the future through the development of next-generation display production line is being prepared, being transferred to China in LCD production facilities can make the most of efficient equipment. Therefore, minimize the cost of new investment and help create the maximum effect to control the detailed behavior of the sequence $\mathrm{H} / \mathrm{W}$ and $\mathrm{S} / \mathrm{W}$ system was installed on the production line. In addition, Fast-evacuating the structure proposed for the Vacuum pump, Pump control circuit design and experimental results has been completed.
\end{abstract}

Key Words : Silicon Pump, Fast-evacuating, Vacuum pump, Pump Control

\section{1. 서론}

$\mathrm{LCD}$ 는 화소 하나 하나가 반도체로 구성돼 생산과정 에서 정밀한 장비 제어가 요구되므로 공정제어 장비의 역할이 매우 중요하다. 이와 같이 반도체·디스플레이 생 산 라인에서 효율적인 공정제어 및 디스펜서의 중요성이 커지는 가운데 제조공정에서 디스펜서 및 공정제어 장치 시장을 겨냥한 장비 업체들의 움직임도 빨라지고 있다. 왜냐하면 $300 \mathrm{~mm}$ 웨이퍼나 7/8세대 LCD 라인 등 대형 라
인의 등장으로 개별 웨이퍼나 유리기판 가격도 크게 높 아지면서 불량이 발생할 경우 입는 피해도 함께 커졌기 때문이다. $300 \mathrm{~mm}$ 웨이퍼의 경우 $200 \mathrm{~mm}$ 제품에 비해 웨이 퍼 1 장에 반도체가 2.5 배 가량 많이 집적되므로 가격도 높아질 수밖에 없다.

이러한 대형 $\mathrm{LCD}$ 패널을 대량으로 생산하는 과정에 서 장비 자체는 물론 공정이 복잡할 뿐만 아니라 접촉손 실(Tact Loss), 배경보다 어두운 흑점(Black spot)이나 배 경보다 밝은 얼룩인 백점(White spot), 긁힘 등과 같은 결

본 논문은 2012년도 남서울대학교 학술연구비 지원에 의하여 연구되었음.

"Corresponding Author : Park Hyoung-Keun

Tel: +82-10-3679-6740 email: phk315@nsu.ac.kr

접수일 12 년 07 월 23일수정일 12년 08월 07일게재확정일 12년 08월 09 일 
함이 있게 되면 결국 $\mathrm{LCD}$ 의 해당되는 화소(pixel) 또는 라인(line)에서 색상을 제대로 표현하지 못하게 된다. 따 라서 실리콘 디스펜서 장치의 효율을 높일 수 있는 알고 리즘, 그리고 동시에 공정개선을 위한 제어 알고리즘이 탑재된 장비의 필요성이 국내·외 $\mathrm{LCD}$ 관련 부품 및 장 비 업체에서 대두되고 있다.

본 논문에서는 2장에서 TFT-LCD 패널의 구조와 Color filter 및 액정공정에 대한 분석을 통하여 개발하고 자 하는 실리콘 펌프 및 정밀제어 시스템의 적용방안을 제시하였다. 또한 3 장에서 개발된 시스템에 적용된 기포 제거 알고리즘과 펌프 및 제어시스템을 제시하였다.

\section{TFT-LCD 생산공정}

본 연구에서는 Backlight Unit에서 입사된 백색평면광 을 구동 회로 Unt로부터 입력된 개개 화소의 신호전압에 따라 화소에 투과되는 빛을 제어하여 Color 영상을 표현 하는 역할을 하는 $\mathrm{LCD}$ 의 제조공정에서 Color filter 및 액 정(cell)공정에 필수적인 디스펜서 장치와 정밀 제어시스 템을 개발하고자 한다.

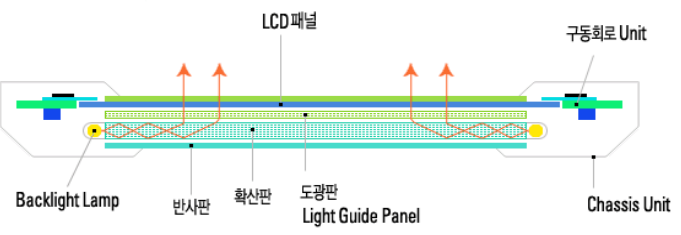

[그림 1] TFT-LCD 패널의 구조

[Fig. 1] Structure of TFT-LCD panel

본 연구에서 목표로 하고 있는 공정의 개념도는 그림 2 와 같다. 또한, 평판 디스플레이 제조 공정 중 그림 3 의 스크린 프린터와 같은 장비는 dispensing이 제대로 이루 어 지지 않을 경우 대면적/다면취 생산이 난이할 뿐만 아 니라 도포량의 불균일성이 상존하는 문제점을 가지고 있 다. 또한 이로 인하여 증가되는 혼색 가능성과 Mask의 오염에 의한 불량률 증가, 스크린 마스크의 관리 및 교체 비용이 증가하는 단점을 가지고 있다.

이러한 문제점들을 해결하기 위하여 정밀한 dispensing 의 제어를 위한 기술의 구현이 필수적이다. 그림 4 와 같 이 실리콘 등의 도포액을 정밀하게 제어함으로써 그림 5 에서와 같이 소성 후 균일성을 유지하고 다면취를 구현 할 수 있을 뿐만 아니라 Start \& End부의 정도 유지가 가 능할 수 있다.

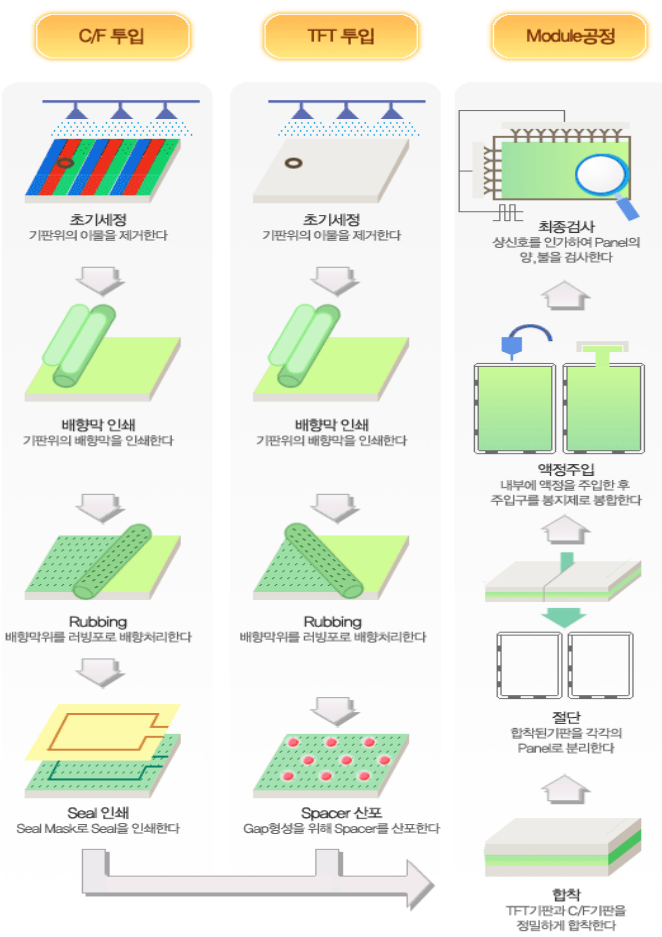

[그림 2] Color filter 및 액정(cell)공정

[Fig. 2] Color filter and cell process

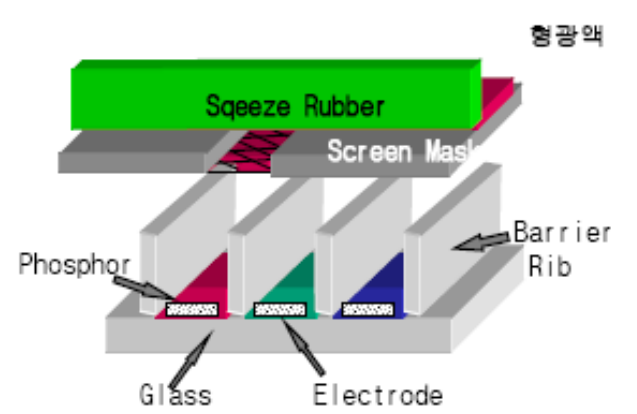

[그림 3] 스크린 프린터 공정

[Fig. 3] Screen printer process

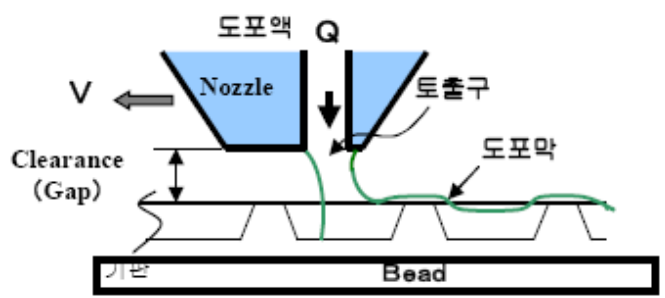

[그림 4] Dispensing 형광막 도포

[Fig. 4] Dispensing fluorescent screen spreading 

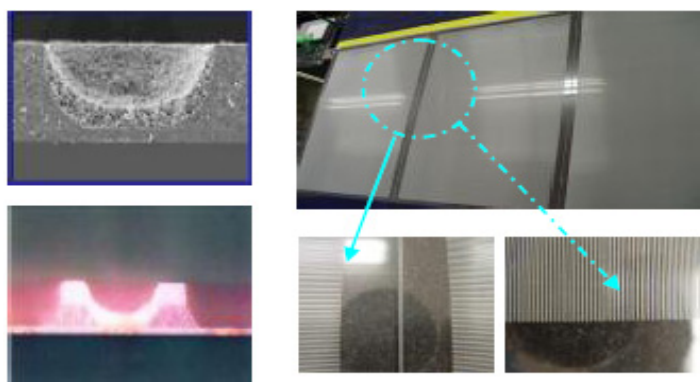

[그림 5] 균일성 및 정도 유지

[Fig. 5] Uniformity and homogeneity maintain

\section{3. 실리콘 펌프 및 제어 시스템 구현}

\subsection{Fast-evacuating을 위한 Vacuum pump 개발}

현재 LCD 공정에서 사용되고 있는 디스펜서의 Bottle 가압방식과 PUMP 방식의 구조는 그림 6, 그림 7과 같다.

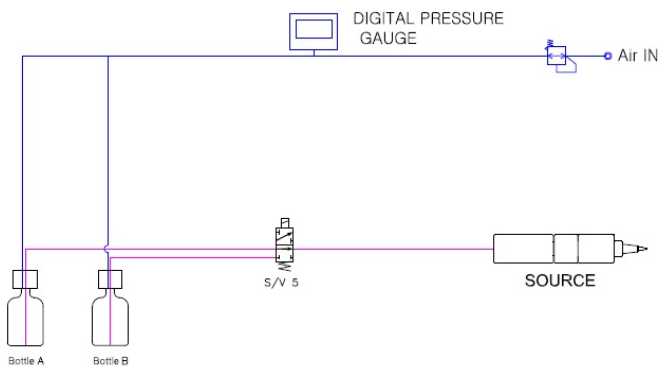

[그림 6] Bottle 가압 방식

[Fig. 6] Bottle pressurizemethod

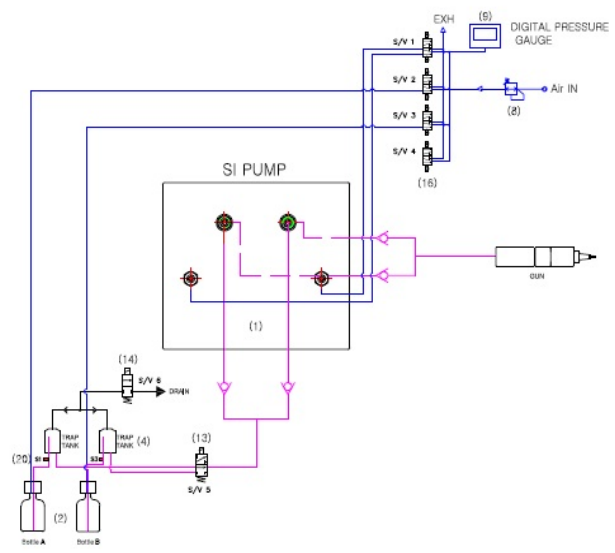

[그림 7] Pump 방식

[Fig. 7] Pump method
이러한 기존의 디스펜서 장치는 다음과 같은 문제점을 가지고 있다.

(1) Bottle 교체 시 작업 시간이 오래 걸리고 작업이 어 렵다. 특히, 외부 Bottle cover를 제거하고, 플라스 틱 Bottle을 손으로 잡고 회전(나사 체결)시켜 제거 하는데 표면이 미끄러워 분리가 어렵고, 시간이 오 래되어 약액이 굳을 경우 분리가 더욱 어렵다.

(2) 잔량 감지 Sensor가 정전 용량 sensor로써 오감지 확률이 높아 미도포 사고가 발생한다.

(3) 정전 용량 Sensor 를 사용함으로써 Bottle 바닥의 잔량을 사용 할 수 없어 원재료 소모가 많다.(약 $1 / 5$ 정도의 약액이 폐기됨)

(4) Bottle 가압 방식임으로 Bottle 내에 고압이 형성되 어 위험하다.

(5) Bottle 가압 방식으로 정량, 정압 제어에 불리하다. 또한, Bottle내 약액 잔량 Level에 따라 유량 변화 가 생길 수 있다.

이러한 문제점을 파악한 후 이를 해결하기 위한 알고 리즘 및 디스펜서의 미세 정량 공급을 위한 제어시스템 을 개발할 뿐만 아니라 이를 이용한 도포 프로세스 전용 제어기를 제작하여 LCD 생산라인에 실장 적용하였다.

약액의 도포량이 LCD 생산 공정에서 균일하게 유지 될 뿐만 아니라 생산 라인의 변경이나 설비의 조절이 필 요 없도록 개발하기 위해서는 Fast-evacuating을 위한 Vacuum pump 및 수율을 저하시키는 주요한 원인이 되 는 기포(Bubble)를 제거할 수 있는 기술이 필수적이며, 이를 해결하기 위한 원인분석 및 해결방안은 그림 8 , 그 림 9 와 같다.

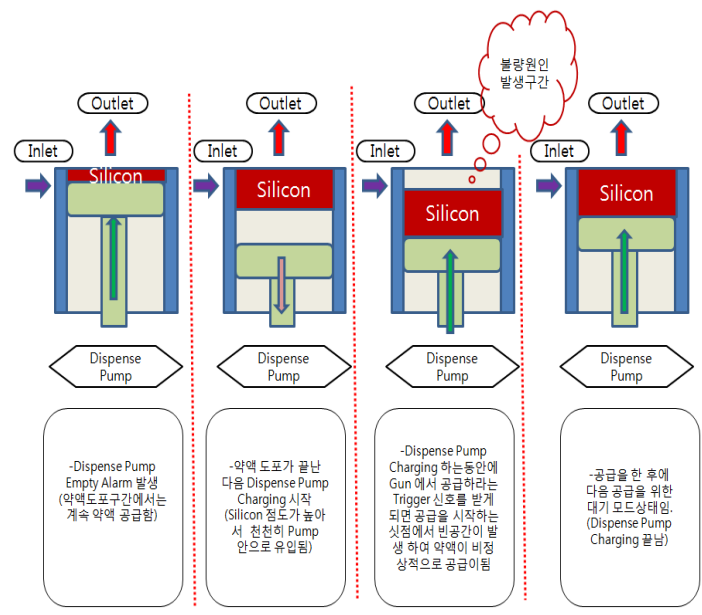

[그림 8] 원인 및 분석

[Fig. 8] Cause and analysis 


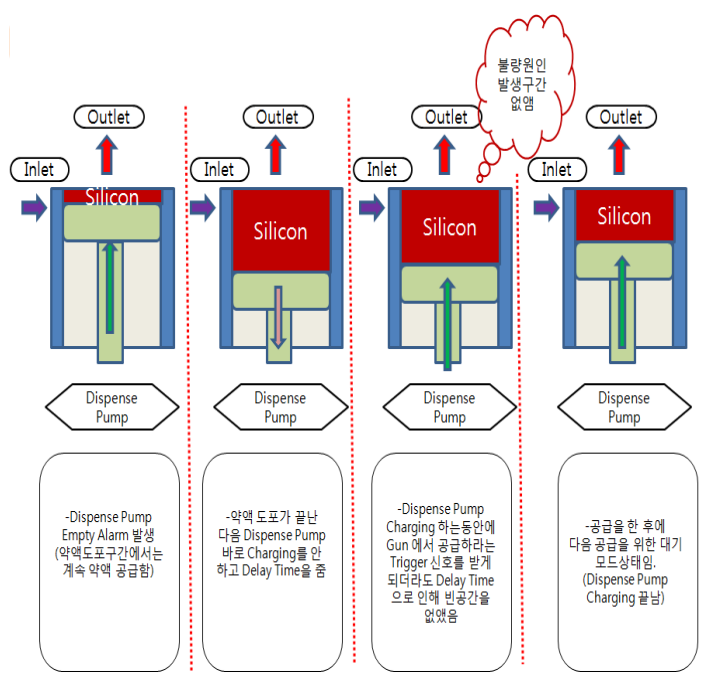

[그림 9] 해결방안

[Fig. 9] Solution

그림 10 은 개발된 Pump의 설계도이다.

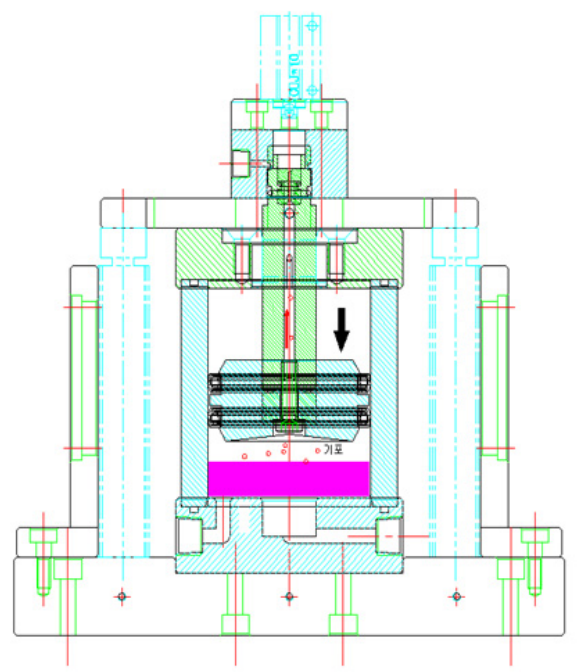

[그림 10] Pump 설계도

[Fig. 10] Pump drawing

그림에서 FEED PUMP 가압시 PUMP 내부의 압력이 생기면서 약액 속에 있는 기포가 위로 올라오므로 PISTON 내부의 관로로 기포를 배출시킴으로써 Valve로 가는 약액에는 기포가 발생하지 않는다.

본 연구에서 설계된 Feed Vacuum Pump와 Dispense Vacuum Pump의 단면도는 그림 11, 그림 12 와 같다.

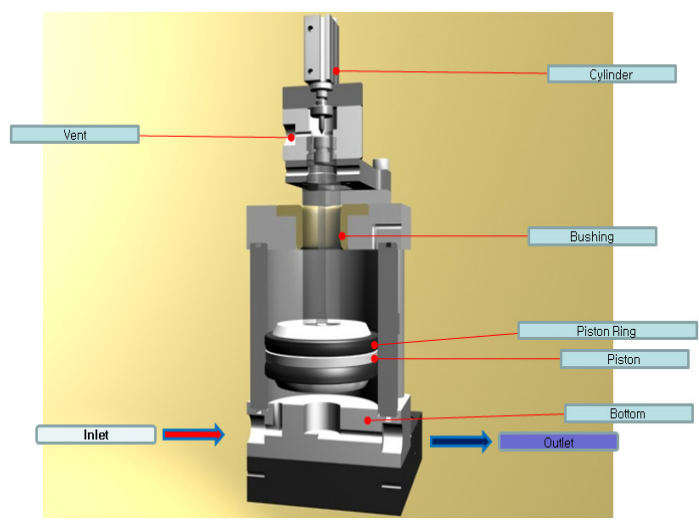

[그림 11] Feed Vacuum Pump 단면도

[Fig. 11] Feed Vacuum Pump cross-sectional drawing

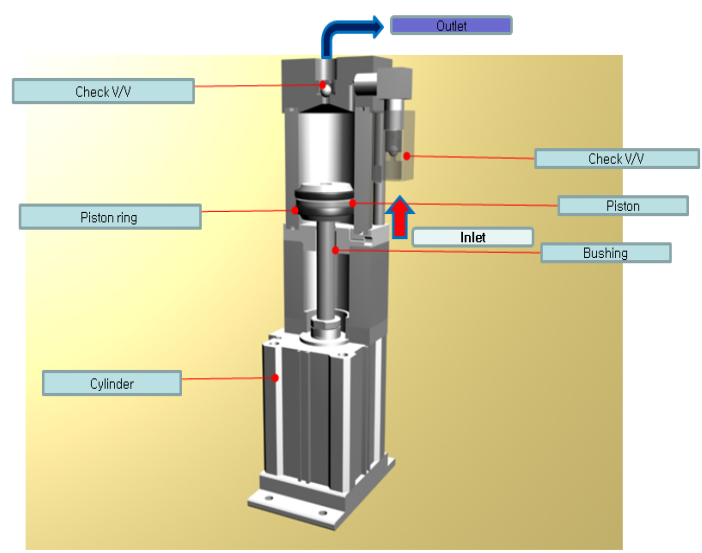

[그림 12] Dispense Vacuum Pump 단면도

[Fig. 12] Dispense Vacuum Pump cross-sectional drawing

\subsection{Pump control board design}

본 연구에서는 저점도에서 고점도에 이르는 다양한 약 액을 드립(drip)없이 고속 정량 충진하고 미세 밸브제어 가 가능하도록 ATmega128 마이크로프로세서를 이용하 여 control 회로를 설계하였다. 이를 통하여 충진조건 설 정, 퍼징(purging)을 간편하게 할 수 있을 뿐만 아니라 작 동 중에도 조건 변경이 가능하도록 개발하였다. 토출 (Evacuating)시간은 타임 파라미터 설정으로 조절되며, 토출량의 미세한 증감은 설정시간과 토출량의 상관관계 에 따라 쉽게 조절된다. 또한 밸브 컨트롤러는 호스트 컴 퓨터나 릴레이로 부터 5-24VDC의 순간전압을 입력받아 토출작업을 시작하며, 공정이 완료된 후 호스트 컴퓨터에 공정 완료 신호를 보내준다.

특히 마이크로프로세서에 내장된 Flash Memory에 설 정치를 기억할 수 있도록 하였으며, 양방향 밸브 컨트롤 이 가능하다. 이러한 컨트롤회로는 독립적인 공정장비의 
패널 및 브래킷에 설치 가능하도록 소형화하였다.

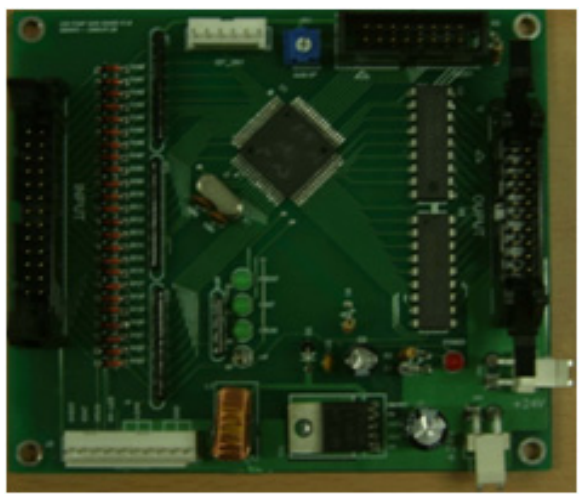

[그림 13] 개발된 밸브 컨트롤 보드

[Fig. 13] Developed valve control board

\section{4. 결 론}

본 논문에서는 Backlight Unit에서 입사된 백색평면광 을 구동 회로 Unt로부터 입력된 개개 화소의 신호전압에 따라 화소에 투과되는 빛을 제어하여 Color 영상을 표현 하는 역할을 하는 $\mathrm{LCD}$ 의 제조공정에서 Color filter 및 액 정.(cell)공정에 필수적인 실리콘 펌프와 정밀 제어시스템 을 제안하였다. 본 연구를 통하여 향후 본격생산을 준비 중인 차세대 디스플레이 생산라인뿐만 아니라 중국으로 이전중인 $\mathrm{LCD}$ 생산 설비에도 진출이 가능할 것으로 판 단된다.

\section{References}

[1] Leslie KE. Binks RA. et. al., "Three component spinner magnetometer featuring rapid measurement times", IEEE Transactions on Applied Superconductivity, Vol. 11, No. 1, pp.1051-8223, Mar. 2001

[2] Villegas I, Napolitano P., "Development of a continuous-flow system for the growth of compound semiconductor thin films via electrochemical atomic layer epitaxy", Journal of the Electrochemical Society, Vol. 146, No. 1, pp. 117-124, Jan. 1999

[3] S. W. Jeong, Y. K. Kim, S. M. Lee, Y. T. Ko, "Atmospheric corrosion monitoring with Time-OfWetness(TOW) sensor and electron resistance sensor," in CSSK Conference, 2001.

[4] J. H. Bae, T. H. Ha, H. G. Lee, "The Development of
Remote Corrosion Monitoring and Automatic Control System for Maritime Matallic Structures," in CSSK Conference, 2000.

[5] Kim C. G, Kim et, al., "Driving cold cathode fluorescent lamps in parallel", Electronics Letters, Vol. 41, Issue 4, pp. 163-164, Feb. 2005

[6] J. Y. Hwang, "Liquid crystal aligining capabilites and EO characteristics of the photoaligned TN-LCD on a photo-cross linkable polyimide based polymer", Mol. Liquid Crystal, No. 412, pp.259-268, 2004

[7] K. N. Choi, "Area-Mura Detection in TFT-LCD Panel", IS\&T/SPIE Symp. on Electronic Imaging, Vision Geometry XII, pp.151-158, Jan. 2004

[8] Y. B. Kim, B. Y. Kim, J. H. Seo, J. W. Kim, "A Study on the Development of a Control and Monitoring System for Impressed Current Corrosion Protection," in Journal of KSPSE, Vol.10, No.2, May 2006.

[9] J. H. Bae, T. H. Ha, H. G. Lee, D. K. Kim, "The Development of Remote Corrosion Monitoring and Control System for Oil Tank by using the High Efficiency CP Rectifier," in KIEE EMECS Conference, Nov. 2001.

[10] H. S. Jung, A Study on the Optimization of Silicon Antiresonant Reflecting Optical Waveguides (ARROW) for Integrated Optical Sensor Applications, Journal of The Institute of Webcasting, Internet and Telecommunication, VOL.10No.5, pp.153-160, October 2010.

[11] Y. d. Lee, I. s. Koo, PDA System for Maximizing the Efficiency of Smart Pallet Based Parts Delivery System, Journal of The Institute of Webcasting, Internet and Telecommunication, VOL.10No.4, pp.115-120, August 2010.

\section{박 형 근(Hyoung-Keun Park)}

[정회원]

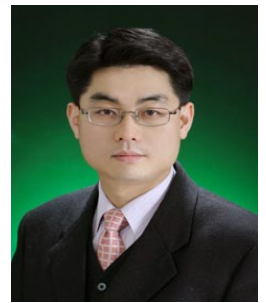

- 1995년 2월 : 원광대학교 대학원 전자공학과 (공학석사)

- 2000년 2월 : 원광대학교 대학원 전자공학과 (공학박사)

- 1998년 5월 2001년 9월 : (주) 미디어서브연구소 선임연구원

- 2005년 3월 현재 : 남서울대 학교 전자공학과 교수

<관심분야>

마이크로프로세서응용, 임베디드시스템, SOC 